\title{
Vida y obra filosófica de Xavier Zubiri, Pedro Laín Entralgo e Ignacio Ellacuria
}

\author{
Sergio Arturo Cañas López \\ Departamento de Salud Pública \\ Universidad Centroamericana (UCA) \\ San Salvador
}

\begin{abstract}
Resumen
Esbozar las entretejeduras biográficas de Zubiri, Lain y Ellacuria obliga a tomar prestada la anécdota en la que el propio Zubiri asoció el significado de su nombre al destino intelectual de su vida y al sentido último de su propia obra. Asi, biblioteca (Apalategui), puente (Zubiri) y casa nueva (Xavier) son simbolos que también son validos para Lain y Ellacuria, por lo prolifico $y$ fecundo de sus producciones (biblioteca), por sus infatigables esfuerzos por conseguir la reconciliación y la solución negociada a conflictos (puente) y por la laboriosidad creativa con la que nos legaron para el siglo XXI sus innovadoras aportaciones en el quebacer bumanista y filosófico, producto de sus prodigiosos talentos (casa nueva).

Abstract

The biographies of Zubiri, Lain and Ellacuria remind when Zubiri associated the meaning of his Basque names to bis intellectual destiny and to the sense of his work. Thus, library (Apalategui), bridge (Zubiri) and new home (Xavier) are symbols that also are valid for Lain and Ellacuria. This happens because of their prolific work (library), their struggle for reconciliation (bridge), and their innovative contributions to the bumanistic and philosophic work for the $21^{\prime \prime}$ century (new home).
\end{abstract}


En anterior artículo² dimos inicio al ejercicio de inscribir a Laín Entralgo en la mejor tradición cultural hispánica del siglo XX, destacando su invaluable producción en los terrenos compartidos por la Medicina, la Historia y la Antropología en la comprensión y estudio de la condición de práctica social radicada en la esencia misma de la Medicina.

A consecuencia de su constante interrogar sobre la índole de la práctica médica, Laín Entralgo -al cuestionarse el lugar y quehacer de dicha práctica- arribó a conclusiones fundamentales sobre cómo debe concebirse la medicina a fin de ser fiel a sus más nobles propósitos. Laín, al referirse a ella, señalaba más apropiado conceptuarla y ejercerla como antropología médica, tendiendo así un puente hacia las humanidades médicas, pues de esta forma la medicina intentaba de mejor forma una aproximación integral al ser humano ${ }^{3}$

Sería sin embargo incompleta cualquier aproximación a Laín destacándole sólo en la vertiente médica en donde comparte reconocimientos en la misma línea que lo recibieron Letamendi, Miguel Servet, Ramón y Cajal, Del Río-Hortega, Gregorio Marañón y Carlos Jiménez Díaz. También destacó como escritor y ensayista junto a Ramón Menéndez Pidal, Eugenio D’Ors, Pío Baroja y Américo Castro, sin que fuera menos importante su contribución a la producción filosófica en la vertiente de Unamuno, Ortega y Gasset y Xavier Zubiri". Desde esta última vertiente intentaremos destacar su relación personal e intelectual con Zubiri y con Ignacio Ellacuría.

Esbozar las entretejeduras de las circunstancias biográficas de Zubiri, Laín y Ellacuría me obliga a tomar prestada la anécdota citada por San Baldomero ${ }^{5}$, en la que, medio en serio y medio en broma, el propio Zubiri asoció el significado de su nombre al destino intelectual de su vida y al sentido último de su propia obra, según lo cuenta su esposa Carmen Castro.

En euskera, el significado de su nombre y dos apellidos es como sigue: Xavier significa "Casa Nueva", que como es sabido era el apelativo con el que se designa en Navarra al castillo de la familia Jaso, la familia de San Francisco Javier. Por su parte Zubiri, o Subiri, quiere decir en euskera "junto al puente", en tanto que Apalategui tiene el significado de "balda de un armario, o de una estantería", pero que en vasco-francés significa sencillamente "biblioteca". 
Así, biblioteca (Apalategui), puente (Zubiri) y casa nueva (Xavier), son aquí tres símbolos con los que se puede intentar comprender el significado de la filosofía de Zubiri, símbolos que tambien aplican para Laín y Ellacuría, por lo prolífico y fecundo de sus producciones (biblioteca), por sus infatigables esfuerzos por conseguir la reconciliación y la solución negociada a conflictos (puente) y por la laboriosidad creativa con la que nos legaron para el siglo XXI sus innovadoras aportaciones en el quehacer humanista y filosófico, producto de sus prodigiosos talentos (casa nueva).

\section{José Xavier Zubiri Apalategui}

José Xavier Zubiri Apalategui nació en San Sebastián, capital guipuzcoana, a orillas del Unumea, el día 4 de diciembre de 1898. Hizo sus estudios básicos en Guipúzcoa y ya entonces le nació la triple vocación científica, filosófica y religiosa a la que habría de ser vascamente fiel durante toda su vida. Ingresó al Seminario Diocesano para seguir la carrera eclesiástica y fue enviado a Madrid a seguir los cursos, entre 1918-1920, del Seminario Conciliar y la Facultad de Filosofía de la Universidad Central (hoy Complutense). En el Seminario recibió la influencia del sacerdote, filósofo y jurista vasco Juan Zaragueta. En la Universidad Central recibió la influencia del joven catedrático de metafísica José Ortega y Gasset, recién llegado de Alemania, quien comenzaba su largo magisterio universitario y periodístico, empeñado en filosofar a la altura de los tiempos que corrían en Europa ${ }^{6}$.

Entre 1919 y 1921, Zubiri estudió en Bélgica la licenciatura de filosofía y la licenciatura de teología en la Universidad Católica de Lovaina. Allí trabajó con el fenomenólogo belga León Nöel. Durante esos años también viajó por breves períodos a Alemania y a Roma, donde, en 1920, se doctoró en teología por la Universidad Gregoriana. En septiembre de 1921 se ordenó de diácono en San Sebastián luego de lo cual 1921 regresó a Madrid y, bajo la tutoría de Ortega, escribió la tesis titulada: "Ensayo de una teoría fenomenológica del juicio" (Ediciones de la Revista de Archivos, Bibliotecas y Museos, Madrid, 1923) que le dio acceso al doctorado en filosofía. Entre 1921 y 1928 permaneció enseñando e investigando en la Universidad Central y allí, en 1926, ganó las oposiciones a la cátedra de Historia de la Filosofía, vacante desde hacía pocos meses por el fallecimiento repentino de su titular Adolfo Bonilla San Martín. Zubiri tenía para entonces veintiocho años. Se estrenó como catedrático en enero de 1927 y ejerció el curso 1927-28'. 
Dos años más tarde, en 1928, se ausentó de Madrid para emprender un largo e intenso periplo de cuatro años por diversos centros culturales europeos en busca de un saber científico suficiente que le permitiera plantear los problemas de la filosofía de forma realista?.

De 1928 a 1931, Zubiri viaja por tres cursos consecutivos a estudiar en Alemania. De 1928 a 1930, permanece en Friburgo donde recibe dos cursos complementando su formación filosófica con Husserl y Heidegger. En el transcurso de 1930 a 1931 reside en Berlín. En la famosa sociedad científica Kaiser Wilhelm estudia física teórica con tres premios Nobel, Max Plank, Erwin Schrödinger y Albert Einstein. Al volver de Alemania, Zubiri impartió sus clases en aquella facultad de filosofía llamada Facultadlaboratorio, que fue la Facultad de Filosofía de la Universidad Central en la que Manuel García Morente al frente de su Decanato (1931-1936) desarrolló una actividad electrizante de reforma universitaria que posibilitaban los aires de reforma polírica que la Segunda República española había traído consigo en 1931. En los veranos de 1933, 1934, 1935 Zubiri participó también muy activamente con Pedro Salinas, Ramón Menéndez Pidal y Blas Cabrera en la organización de los cursos de verano la Universidad Internacional Santander ${ }^{10}$.

En 1931 retornó a su cátedra de Historia de la Filosofía cuando, en aquellos días de la segunda república española, la Facultad de Filosofía de la Universidad Central atravesaba por un momento estelar. A partir de 1933, comenzó Zubiri a publicar sus ensayos y traducciones de importantes artículos de otros filósofos en Cruz y Raya, la revista que fundó José Bergamín, y en la famosa Revista de Occidente, que fundó Ortega y Gasset"

$\mathrm{Al}$ referirse a su relación con Zubiri, el mismo Laín Entralgo describe ${ }^{12}$ que esta tuvo un comienzo que no fue amistoso propiamente dicho, sino que lo fue de afición; fue una relación primariamente lectiva: la lectura de dos ensayos de Zubiri, entre 1932 y 1936, que reconoce fueron rigurosamente decisivos en su vida intelectual. El primero, "La nueva física", publicado en Cruz y Raya, del cual le interesó la magistral exposición de lo que era la física del átomo (la física más actual, tal como era en 1933) y le cautivó la claridad, el rigor, la profundidad con la cual se pasaba a un replanteamiento del problema de la realidad, del problema de la naturaleza. Junto al ensayo, "En torno al problema de Dios" (Revista de Occidente), dejaron tal impronta en Laín que confiesa que le plantearon una meta vocacional y dedicacional: pensaba para entonces dejar mi 
modestísimo puesto de médico en Valencia y buscar algo en Madrid, donde creía que podía encontrarse con Zubiri y por supuesto - confiesacon Ortega ${ }^{13}$. La guerra civil interrumpió temporalmente esos planes.

Para Zubiri, la etapa de cinco años de investigación y docencia en Madrid, entre 1931 y 1936, quedaría truncada al iniciarse la guerra civil española, el 18 de julio de 1936. Muchos de los filósofos de la llamada "Escuela de Madrid" se vieron urgidos a exiliarse: José Bergamín, Joaquín Xirau, José Ferrater Mora, José Recaséns Siches, María Zambrano, Manuel Granell, José Gaos, el mismo Ortega, lo mismo que otros filósofos como Juan David García Bacca, Adolfo Sánchez Vázquez, Eduardo Nicol, Eugenio Imaz, Augusto Pescador y José Medina Echevarría. Por su parte, a Zubiri lo sorprendió el golpe militar en Roma, donde había contraído matrimonio con Carmen Castro, previa dispensa de sus compromisos eclesiásticos y reducción al estado laical, en la primavera de ese año"${ }^{14}$.

Zubiri había ido a Roma el año 1935, a aprender idiomas orientales; en esa fecha dominaba ya el griego, el hebreo y el latín, aparte del vasco, castellano, alemán, francés e italiano. Pero en aquel momento trataba de aprender, o al menos adquirir familiaridad, con el sumerio, acadio, hitita, iranio y arameo. El orientalista jesuica Antón Deimel, profesor del Instituto Bíblico, le introdujo en la lengua sumeria y el hebraista y arameista, en tanto que siendo profesor en el centro San Anselmo, Centro Universitario de los Benedictinos en Roma, el español Luis Palacios le ayudó en el aprendizaje del arameo ${ }^{15}$.

Presionado por la policía fascista, marchó (de Roma) a Francia, donde dictó cursos sobre temas de filosofía y teología en el Instituto Católico, al mismo tiempo que estudiaba historia antigua y lenguas orientales (con Benveniste, Massignon, Labat, Dhorme, De Menasce y Delaporte) y proseguía sus estudios de física (con Louis De Broglie y los Joliot-Curie), matemáticas (con Cartan), biología y ciencias bíblicas. En París, Zubiri y Carmen hicieron honda amistad con Jacques y Raisa Maritain ${ }^{16}$.

Fue precisamente el 8 de septiembre de 1936, cuando el matrimonio Zubiri abandonó Roma con destino a París En París el matrimonio Zubiri vivió en el Colegio de España de la Ciudad Universitaria hasta otoño de 1938. En París Zubiri siguió trabajando en matemáticas y física. Gracias a Blas Cabrera le admitió en sus clases el premio Nobel de física Luis de Broglie, los Joliot-Curie y Cartan. Marcel Bataillon le presentó a Masignon y al famoso lingüista iranista Benveniste. Jacques Maritain, quien había 
hecho amistad con Zubiri en la Universidad de verano de Santander, le puso en relación con un escogido grupo de orientalistas como Dhore, De Menasce, Laporte y Labat. En junio de 1938, presentado por Masignon y Benveniste fue elegido miembro de la Societé Asiatique. Ese mismo año recibió el diploma de Hautes Études. Maritain hizo que Zubiri diera dos cursos breves en el Institut Catbolique sobre historia de las religiones ${ }^{17}$.

Terminada la guerra civil española, en 1939, al comenzar la llamada segunda guerra mundial, Zubiri regresó a una España donde imperaba el nacional-catolicismo y las cátedras universitarias estaban en manos de clérigos inquisitoriales para quienes él —que nunca fue "nacional", "republicano" o "de la mediación" - resultaba sospechoso. En Madrid, a Zubiri le ofrecieron de nuevo su cátedra, bajo vigilancia. Por dignidad y libertad intelectual prefirió marcharse a Cataluña, a hacerse cargo de la cátedra de Historia de la Filosofía de la Universidad de Barcelona, donde impartió cátedra entre 1940 y $1942^{18}$.

Fue precisamente el 2 de septiembre de 1939, al día siguiente de estallar la segunda guerra mundial, prácticamente indocumentados y en una situación fáctica de apátridas, que el matrimonio Zubiri regresa a Madrid. Por entonces se muestran ya inviables algunas ofertas para seguir estudiando en Upsala y Jenusalén ${ }^{19}$.

No es digerible fácilmente la situación de Zubiri para el nuevo régimen. Un catedrático discípulo de Ortega y Gasset, formado en los renovadores aires filosóficos y científicos europeos, un clérigo secularizado y casado con la hija del intelectual republicano Américo Castro, son ingredientes de una situación personal lo suficientemente problemática en aquel momento como para no gozar de simpatías en el Nuevo Estado nacionalcatólico ${ }^{20}$.

Fue hasta ese 1939 que llegó para Laín Entralgo la ocasión de entablar relación directa con Zubiri. Recurrió Laín a dos personas que lo conocían; una, Miguel Ortega, médico e hijo de José Ortega; la otra, Xavier Conde quien había conocido a Zubiri en la residencia universitaria en la Casa de España de la Ciudad Universitaria de París. Así, en el vestíbulo de un hotel que ya no existe, de nombre "Roma", situado en la Gran Vía se dio el encuentro que Laín confiesa como una experiencia decisiva para el curso entero de su vida intelectual ${ }^{21}$.

No obstante que el matrimonio es bien recibido en Madrid por el ministro de Educación Ibañez Martín. Ello no impide que Carmen Castro 
aparezca en una lista de catedráticos de Instituto destituidos de sus cargos. En la Navidad de 1939 el ministro hace saber a Zubiri que no tiene problemas para quedarse de catedrático en Madrid. Pero el arzobispo de Madrid, Leopoldo Eijo y Garay, hace una interpretación restrictiva del derecho canónico sobre su secularización y fuerza su traslado a Barcelona ${ }^{22}$.

En Barcelona logra, al parecer, gran éxito entre los estudiantes, pero ciertos acontecimientos le llevan a apartarse voluntaria y definitivamente de su cátedra ${ }^{23}$ :

Primero, un día un decano falangista le reprende por emplear su riempo en clase de Historia de la Filosofía en explicar a Kant cuando debe dedicarlo a santo Tomás.

Segundo, el episodio de la tesis doctoral de Julián Marías. Zubiri, como director de la tesis, advierte a Marías que en aquella situación política su lectura puede resultar imprudente. Cuando, a pesar de todo, Marías decide presentar la tesis, Zubiri conoce la animadversión que algunos filósofos de Madrid miembros del tribunal tienen contra él. Opta por no asistir al acto para no perjudicar al alumno y envía un telegrama de apoyo rotundo. Juan Zaragüeta carga con la responsabilidad de defender a Marías ante el tribunal. Una intriga intema del dominico Manuel Barbado, desemboca en el hecho insólito de suspender una tesis doctoral. Además a un joven altamente prometedor pero que no oculta ser discípulo de Ortega y Gasset y de Zubiri.

Tercero, y gota que colma el vaso, un buen día Zubiri recibe la comunicación escrita del Decano de la Facultad con la orden de que los profesores deben comenzar cada clase con declaraciones de apoyo al régimen.

Al final de curso, junio de 1942, ante la incompatibilidad del modelo de Universidad nacional-católica con la necesaria libertad para investigar y enseñar, Zubiri presenta la renuncia a su cátedra de Historia de la filosofía, de la que, por cierto, ya había sido depurado en el año 1937 por el gobierno del Frente popular. Zubiri se convierte así, en lo que Elías Díaz calificó de un exiliado en el interior ${ }^{24}$.

En 1942, tras su renuncia, irrevocable a la cátedra oficial, Zubiri regresó a Madrid. En diciembre de ese mismo año firmó el prólogo de su primer libro: Naturaleza, Historia, Dios, Ed. Nacional, Madrid, 1944. Como primer artículo del libro, escogió precisamente el texto de la conferencia 
"Nuestra situación intelectual" la que había dictado previo a su renuncia, y ubicó tras él gran parte de los escritos que venía publicando en revistas desde $1926^{25}$. Siendo ya manifiestas sus dificultades con el clero nacionalcatólico en el verano de 1943 y estando en prensa el texto de Naturaleza, Historia, Dios, su impresión tarda todo un año, pues los censores van dando el imprescindible "Nihil Obstat" artículo por artículo. Sin embargo, a pesar del éxito editorial que la obra ya había obtenido en 1944, las revistas del Consejo Superior de Investigaciones Científicas (Arbor y la Revista de Filosofía) ni siquiera mencionan el libro aún no siendo hasta entonces abundante la producción bibliográfica española en el campo de la filosofía ${ }^{26}$.

Al renunciar a la cátedra el matrimonio se queda en Madrid con 125 pesetas como toda reserva de la economía familiar. El cheque de su amigo Alejandro Araoz equivalente a un año de sueldo, las traducciones, las lecciones particulares, las colaboraciones en la revista Escorial y la edición de Naturaleza, Historia, Dios, son las primeras ayudas para la supervivencia" ${ }^{27}$.

En estas circunstancias, es que Laín aloja en su casa a los Zubiri, ocasión en la que el mismo Laín destaca como sigue los detalles que rodearon el origen de los cursos privados iniciados por Zubiri en $1942^{28}$ : "Zubiri fue profesor titular, catedrático (con pleno derecho de sede), de Filosofía en la Facultad de Filosofía de Barcelona dos años (1940-42). Entonces, por varias razones, la vida en Barcelona se le hizo penosa. Llegó por ello a tomar una decisión en cierto modo heroica: de Barcelona, se viene a Madrid, a todo riesgo, sin nada. Mi amistad con él en 1942 que ya se había hecho entrañable y mi corresponsabilidad de amigo con su destino, me hicieron pensar en esta venida a Madrid como en extremo arriesgada desde el punto de vista económico. Él, que era hijo de una familia acomodada, se había convertido de pronto en hombre impecune. Vino aquí sin dinero y le ofrecimos, mi esposa y yo, nuestra casa. Mientras tanto, hice todo lo posible por conseguir que la situación tuviera pronta solución. Me dirigí al entonces Ministro de Educación, Don José Ibáñez Martín. Su respuesta fue negativa. La segunda tentativa fue en el Consejo de Investigaciones. El ministro más o menos estaba dispuesto, pero el entonces director del Instituto Luis Vives, el dominico Padre Barbado se opuso totalmente. La tercera intentona fue pensar en la Dirección General de Relaciones Culturales del Ministerio de Asuntos Exteriores. La nueva gestión también fracasó. Ante todo esto, determiné una idea que contrasté 
con el médico Jiménez Díaz y un día nos reunimos en un aguaducho de El Retiro y juntos los dos le propusimos: "Mira, Xavier, tu misión es hacer filosofía, enseñarla, ¿por qué no organizamos unos cursos, privados, en los cuales los asistentes con una asignación módica puedan ayudarte a vivir"? Se aceptó, y así empezaron los cursos de la Unión y el Fénix, que luego pasaron a la Cámara de Comercio". De allí en adelante, la amistad Laín-Zubiri se consolidó en una fecunda vertiente de producción filosófica que se constituyó en un punto de renovados encuentros entre ambos.

A partir de 1945 la influencia de Zubiri comenzó a hacerse sentir sobre cada vez más amplios sectores de la intelectualidad española, debido a la serie de cursos extrauniversitarios anuales a los que acudía fielmente un público heterogéneo. La sala de conferencias de la Sociedad de Estudios y Publicaciones, en la Plaza del Rey de Madrid, se constituyó así en la mejor cátedra de filosofía que nunca tuvo la institución universitaria española de entonces ${ }^{29}$.

A los cursos privados también acudía, por invitación expresa, un público interdisciplinario de médicos, ingenieros, psicólogos, arquitectos, teólogos, y, por supuesto, filósofos, con los que se constituyó el Seminario de Filosofía Xavier Zubiri. Entre ellos estaban Ignacio Ellacuría, Alfonso López Quintás, Carlos Fernández Casado, Diego Gracia Guillén, Alberto del Campo, Carlos Baciero y José Montserrat, María Riaza, Pedro Laín Entralgo, Antonio Babolín, Enrique Rivera, Germán Marquínez Argote, Antonio Pintor-Ramos, Hans Widmer, entre otros ${ }^{30}$.

Con todo, el acoso hacia su persona y hacia su obra persistieron aún por largo tiempo al par del asedio contra Ortega y Gasset y su legado filosófico. De 1942 a 1958 hay una campaña de desprestigio hacia la obra de Ortega para prohibir su lectura y distribución en España por parte de algunos representantes del clero. El acoso alcanza su punto culminante en 1958, después de la muerte del filósofo, cuando el dominico Santiago Ramírez pretende "demostrar que el pensamiento filosófico de Ortega es contrario a los dogmas y principios de la religión católica y que su lectura es peligrosa para quienes aceptan la fe y el magisterio de la iglesia". Zubiri había hecho profesión pública de orteguismo el 18 de marzo del año 1936 en las páginas de $E l$ Sol con un artículo titulado Ortega, maestro de filosofía , y otro el 19 de octubre de 1955 en $A B C$, con motivo de la muerte de Ortega. Consecuencia: la operación que lleva al Indice de libros prohibidos a La agonia del cristianismo y el Sentimiento trágico de la vida, de Miguel de Unamuno se intenta también ahora contra Ortega y contra Zubirin'. 
También se hacen ataques directos hacia el artículo En tomo al problema de Dios ni más ni menos que el señalado por Laín como el primer contacto documental con Zubiri que tan profunda impronta dejara en su vida.. Reviste especial virulencia el ataque del dominico Teófilo Urdánoz en el año 1946 desde la revista La ciencia tomista. Urdánoz coloca a Zubiri dentro del antropocentrismo existencialista, que considera revolucionario y totalitario, en comunión espiritual directa con las ideas de Unamuno y Ortega. El dominico le niega el pan y la sal. $\mathrm{Ni}$ como historiador de la filosofía, a la que considera "historia de las aberraciones humanas", ni como pensador que apunta a un sistema propio le concede un lugar en el panorama filosófico del momento ${ }^{32}$.

Hay que decir, no obstante, que también recibe reconocimientos. En el año 1953 recibe un Homenaje (revista Alcala) con motivo de sus 25 años de profesor universitario. El 1968 otro Homenaje más amplio con motivo de sus setenta años lleva las firmas de sus amigos de siempre, de prestigiosos intelectuales y científicos españoles del momento, del exilio exterior y de Europa ${ }^{33}$.

En 1973, la persona y la obra de Zubiri obtienen otro decisivo reconocimiento público al recibir y aceptar la invitación del prepósito general de los jesuitas Pedro Arrupe para dar un curso de doce lecciones sobre El problema teologal del hombre en la Universidad Gregoriana de Roma. En realidad, no era la primera vez que Arrupe reconocía el valor de Zubiri y de su filosofía, puesto que desde 1965 había dispuesto que el jesuita Ignacio Ellacuría viniera a temporadas desde El Salvador a Madrid para ayudar a Zubiri en la publicación de sus escritos inéditos ${ }^{34}$.

Si duro es el exilio interior en su casa madrileña, aún puede decirse que Zubiri sufre otro exilio, sino más dramático que el de la Universidad, no por ello menos sentido. Hasta 1980 no ha dado nunca ninguna lección en su tierra natal. Cuando el día primero de octubre de ese año, a sus 81 años, Zubiri pronuncia su discurso como Doctor Honoris Causa en teología por la Universidad de Deusto con motivo de cumplirse el centenario de su Facultad de Teología, los jesuitas ponen así fin a su destierro de Euskadi ${ }^{35}$.

Casi a las puertas de la muerte llegan los reconocimientos oficiales. En noviembre de 1979 el Presidente de la República Federal Alemana condecora a Zubiri con Das Grosse Verdienst Kreuz en su más alta categoría para quien no sea Jefe de Estado. El día 18 de octubre de1982 Xavier 
Zubiri y su amigo el premio Nobel Severo Ochoa reciben de S. M. el Rey el Premio Ramón y Cajal a la investigación otorgado por vez primera por el Ministerio de Educación y Ciencia ${ }^{36}$.

Zubiri muere el 21 de septiembre de 1983. Hay en torno a su muerte un aspecto simbólico que no pasa desapercibido para la prensa: el entierro por voluntad propia en el cementerio civil, junto a su suegro, el político e intelectual heterodoxo en tantos aspectos, Américo Castro. El hecho es todo un símbolo de lo que representa el pensamiento y la vida de Zubiri. Con la decisión de ser enterrado en el cementerio civil, aun siendo creyente cristiano, Zubiri dicta la última lección de su secularizada filosofía: tiende un puente entre la orilla llamada sagrada y la orilla llamada profana afirmando su radical unidad por la religación al poder de lo real ${ }^{37}$.

Ponderando la obra zubiriana, Laín Entralgo a propósito del centenario del nacimiento del filósofo apuntaba ${ }^{38}$ :

Pensaba entonces y sigo pensando ahora que la obra intelectual de Zubiri constituye un legado valioso para tres grupos de hombres: los filósofos propiamente dichos y los meramente aficionados al pensar filosófico, los hombres de ciencia y los lectores deseosos de entender en su integridad la realidad del cosmos y, en ella, la del ser humano.

I. El legado a los verdaderos filósofos y a los seriamente aficionados a la filosofía consiste en un sistema filosófico a la vez nuevo y abierto al futuro, compuesto por estas tres piezas maestras:

$\mathbf{1}^{\mathbf{2}}$. Una metafísica fundamentalmente edificada desde una metódica y rigurosa sustitución del concepto aristotélico de "sustancia", tradicional desde su creación, por los de "sustantividad" y "estructura". Éste fue, reducido a su nervio, el tema central de Sobre la esencia. No puedo pasar aquí de esta sumarísima indicación.

$\mathbf{2}^{\mathbf{a}}$. Una teoría del conocimiento, basada en la concepción de la inteligencia humana como "inteligencia sentiente", esto es, como una actividad psíquica en la que, contra la tópica doctrina tradicional, unitariamente se funden "lo inteligible" y "lo sensible". Ampliamente se halla expuesta en tres volúmenes: Inteligencia y realidad, Inteligencia $y$ logos e Inteligencia y razón.

$3^{2}$. Una cosmología a la vez dinámica -mejor: dinamicista- evolutiva y estructural, basada en la concepción de la realidad primaria del Cosmos como dinamismo. Parte central y cimera de esta cosmología es una 
antropología capaz de superar la tradicional y al parecer irreductible oposición entre el dualismo (el hombre, alma y cuerpo, espíritu y materia) y el monismo materialista (el hombre sólo materia).

II. El legado de Zubiri a los hombres de ciencia tiene, a mi modo de ver, dos aspectos complementarios: con un extraordinario conocimiento de varias ciencias básicas - la matemática, la física, la biología, la ligüística一, Zubiri muestra a los científicos que su saber, cuando es exigentemente poseído y pensado, necesariamente conduce a una visión filosófica de lo real; y les enseña, por otra parte, que un cultivo ambicioso de la filosofía exige tener muy en cuenta lo que las ciencias positivas dicen de la realidad. Con fidelidad a esa íntima convicción ha elaborado Zubiri todo su sistema filosófico, desde la confección de Sobre la esencia. Sin el apoyo en la ciencia, la filosofía, obligada a vivir de sí misma y de su historia, se seca, ha escrito el filósofo Paul Ricoeur. Desde su temprano ensayo Ciencia y realidad, así lo ha demostrado la obra de Zubiri.

III. Desde la publicación de Sobre la esencia, se ha hecho tópica entre nosotros la idea de que la de Zubiri es una filosofía abstrusa, sólo accesible y sólo interesante para quienes por una razón o por otra se han decidido a ser "zubirianos". No lo pensarán así -mejor. no deberán pensarlo así- los que por vocación y oficio se han dedicado a la filosofía, si se acercan a los libros de Zubiri con auténtica voluntad de intelección.

"En suma", continúa Laín, "el triple legado el de Zubiri a la cultura del siglo XXI se resume así: "para los cultivadores de la filosofía, un sistema filosófico nuevo y abierto; para los hombres de ciencia, una vía para radicalizar filosóficamente su propio saber; para los meramente aficionados a profundizar lo que saben, una amplia colección de lecturas sugestivas. Pero no se acaba aquí el legado de Zubiri. A algunos, entre los que me cuento, nos ha dejado algo más: el vivo recuerdo de un amigo insustituible ${ }^{\mathrm{n} 9}$.

\section{Pedro Laín Entralgo}

Llegado el momento de desplegar nuestro abordaje sobre don Pedro Laín Entralgo, iniciaremos con lo que Julián Marías, a propósito de este autor, $\operatorname{acota}^{40}$ :

"No es fácil comprender el conjunto de la obra intelectual de Pedro Laín Entralgo. Su larga duración de más de setenta años va desde el final 
de la guerra civil hasta su muerte hace unos días; su amplitud y variedad puede enmascarar su coherencia, la convergencia de sus muchas dimensiones; la clave de su unidad en un proyecto intelectual de excepcional valor".

En muchos sentidos Laín hace pensar en Gregorio Marañón, médico como él, atento a la realidad española y sus problemas, con una visión estrictamente personal de todo ello, con una formación digna de los más abarcadores y profundos humanistas de diversos siglos. Estas preocupaciones llevaron a Laín al campo de la filosofía; nunca tuvo pretensión de filósofo, pero si se mira con atención su obra se descubre que es parte importante de la creación filosófica española de los últimos decenios, con la incorporación de gran parte de su tradición antigua y, por supuesto, de su renacimiento extraordinario en nuestro siglo desde Unamuno y Ortega, con la aportación absolutamente esencial para Laín de Zubiri, a quien siempre consideró su maestro.

En la última fase de su larga vida, la obra de Laín recobró la unidad originaria de sus diversos flancos. El problema de la unidad del hombre, del sentido unitario de sus diversas dimensiones, de la realidad del cuerpo, algo decisivo para el profundo conocimiento de un médico excepcionalmente profundo y competente, y el carácter radicalmente personal de lo humano. Esto hace que varios volúmenes de la obra de Laín, publicados en la Editorial Galaxia Gutemberg del Círculo de Lectores, sean estrictamente "antropológicos", convergencia de la visión científica, empírica, de lo humano con el sentido predominantemente filosófico del análisis de la persona humana.

A última hora, esta amplia y muy significativa parte de la obra de Laín viene a iluminar el conjunto de su producción. Las innumerables páginas que escribió en los últimos años iluminan el ingente conjunto de sus escritos desde los años inmediatos a sus comienzos en la década de los cuarenta. El propio Laín ha vuelto a reunir e interpretar desde el nivel de su madurez la impresionante serie de estudios que había ido elaborando desde las diversas solicitaciones que las múltiples facetas de su personalidad le habían ofrecido y planteado.

Esta consideración permite una comprensión global de una obra cuya extensión y variedad podría llevar a una visión fragmentaria y en definitiva inadecuada de su pensamiento. Es particularmente interesante el que la maduración de Laín lo haya llevado a la conexión final de los muy diversos elementos que han compuesto su obra. Ese carácter unitario, vitalmente 
convergente, de su obra escrita descubre el sistematismo interno de un pensamiento cuyo último sentido filosófico trasparece al final de una larga carrera intelectual. Me parece esencial retener estos rasgos que no son añadidos por una consideración exterior a su obra, sino que aparecen si se la considera en serio y en su conjunto. Se puede leer la obra de Laín de tantos años, movida por tantos problemas concretos y aparentemente independientes, y se descubre lo que es una obra intelectual que responde a una persona concreta, a una vida muy larga, sometida a tantas presiones, solicitaciones, recursos; en una palabra, a una trayectoria ejemplar, realizada en condiciones particularmente complejas y dramáticas, que descubren el sentido de una etapa de nuestra historia que sería decisivo comprender y asimilar en su complejidad y en el sentido unitario que adquiere al verla realizada en una biografía.

En opinión de Nelson Orringer y más referido a las etapas de la producción intelectual de Laín, comenta ${ }^{41}$ :

El pensamiento todo de Laín puede dividirse en tres períodos, cada uno basado en una diferente virtud teologal que presta su tono o talante a todos sus actos y palabras. Entre 1935 y 1948, el catolicismo español, afectado por la politización de todo el país, entra en una fase agresiva tras una sangrienta guerra civil. Entonces, los actos y los pensamientos de Laín afirman la fe sobre todo. Entre 1948 y 1958, Laín se desespera ante la intolerancia del franquismo, y busca la esperanza en la soledad fértil de un intenso profesionalismo. Pero su mezcla de desesperación y de esperanza da paso en 1958 a una tercera época, la del amor, que dura hasta la fecha de su muerte. Esta madurez va marcada por una apertura a los placeres y a la creatividad de la amistad.

Quizás el libro más universal producido por Laín en su primera época, la fase de la fe católica, ha sido Antropología en la obra de fray Luis de Granada (1946). Este es un hermoso estudio de la teoría del hombre entresacada de los escritos devotos del humanista dominico del siglo XVI. El libro más leído y editado de Laín ha salido también de este primer período. Se trata de la Generación del 98 (1945). En la España de Franco, el título de este libro sonaba a izquierdismo. Pero la diestra mano de Laín, siempre concilatorio, lleva al lector a una posición moderada desde la cual interpretar sus contenidos. Los franquistas menos moderados veían a los noventayochistas como rojos. Laín contravenía esta visión presentándolos abiertos a Europa al comienzo, pero preocupados en su madurez por creencias firmemente arraigadas. 
En la época media de la producción de Laín, 1948 a 1958, ya no domina tanto la preocupación por la fe, sino la esperanza. Viene a la superficie la noción del ser humano como adolescente permanente. En el libro más memorable de este período, La espera y la esperanza (1956).

En torno a 1950, pone sus esperanzas en cualquier democracia representativa que el régimen de Franco pudiera tolerar. Cuando acepta en 1952 el rectorado de la Universidad Central madrileña, ve la solución al problema de España en la 'concorde tensión [...] de las diversas 'alas' de un mismo movimiento [nacional]". Con esperanza desesperada, Laín pretende una España en que convivan amorosamente "Cajal y Juan Belmonte, la herencia de San Ignacio y la estimación de Unamuno, el pensamiento de Santo Tomás y el de Ortega [y Gasset]".

No hace falta exponer aquí todos los motivos por los cuales, en 1956 Laín dimite como rector, herido por la intransigencia de la derecha franquista, que le acusa, como si fuera Sócrates, de estar contribuyendo a "envenenar la mente" de la juventud universitaria con su permisividad hacia el estudio de Unamuno y de Ortega. La historia actual de España hoy le da la razón. Y presentó su dimisión a tiempo para iniciar un nuevo vuelo intelectual, el período más maduro de su pensamiento sólo dos años después en 1958. La tercera etapa del pensamiento de Laín trata principalmente de la amistad o amor como hábito radical de la existencia humana; esta tercera etapa puede subdividirse en dos subfases:

En la primera subfase, la que comienza en el 58 y termina en el 86, Laín publica cuatro volúmenes que responden a las complicadas cuestiones planteadas por el amor o la amistad: los dos tomos de Teoría y realidad del otro (1961), La relación médico-enfermo (1964) y el opúsculo precioso Sobre la amistad (1972). El encuentro de un hombre con otro sirve como la base de la relación médico-enfermo, y genera todas las ideas de Laín sobre la amistad.

En su libro Teoría y realidad del otro (1961), estudia el encuentro de un hombre con otro lo que le sirvió de base para el estudio de la relación médico-enfermo, y que generó todas las ideas de Laín sobre la amistad. Publicado inicialmente en 1961 (Revista de Occidente) y luego en 1983 y 1988, el libro Teoria y realidad del otro es un "volumen de tomo y lomo", como suele describirse el libro con muchas páginas. En efecto, es un ensayo que contiene el más exhaustivo estudio filosófico-antropológico que se haya escrito sobre el "otro"; es decir, sobre la persona distinta de aquella que habla. Su interés por tal asunto surgió de una reflexión sobre 
la relación entre el médico y el enfermo, sobre la convivencia con otro durante el ejercicio de la medicina. Acá es donde puede identificarse la elaboración más fecunda de lo que Laín, usando un neologismo, llama "vida en projimidad", esa ayuda libre, activa y desinteresada al otro que tan genialmente se ilustra con la portada del mismo libro (Alianza Editorial-Alianza Universidad) mediante la pintura El albañil berido o accidentado (Goya) en donde dos de ellos llevan en silla de manos a un tercero que se halla desgonzado a consecuencia de un accidente de trabajo en la construcción de un edificio, lienzo en el que la expresión de la cara de los dos obreros samaritanos es todo un tratado de filantropía, de solidaridad con "el otro". Esta escena, sin duda, es la conjunción del yo, del tú y del nosotros, tan profundamente tratada por Laín en la obra ${ }^{42}$.

Para Laín, continúa Oringer $^{43}$ la amistad consiste en una relación amorosa entre dos personas basada en mutua benevolencia, "benedicencia", beneficencia y "benefidencia"; con otras palabras, buena voluntad, palabras animadoras, actos benéficos y confianza con confidencias o secretos contados entre ellas. Cada cual, médico y enfermo, se afirma a sí mismo siendo el otro. Y sólo en este sentido habla Laín de la relación médicoenfermo como un "compañerismo de viaje".

Queda por examinar la segunda subfase, la que sigue, para Oringer"4 basada en la virtud teologal del amor, pero que reduce al ser humano a un cuerpo amante y amado. Por lo menos desde 1984, Laín, adolescente perpetuo, siempre inquieto y deseoso de estrenar nuevas formas de pensar, ha ambicionado producir una revolución científica. Ha querido inventar una nueva teoría integral del cuerpo humano. Laín llevó a cabo su gigantesco proyecto en el verano de 1988 en Cádiz, donde escribió a mano lo que había de ser su excelente libro El cuerpo bumano. Teoría actual.

\section{Ignacio Ellacuría}

Para introducir a Ignacio Ellacuría en la revisión hecha por este artículo resulta idóneo asistirse de la semblanza que de él hace Ricardo Falla, S.J. ${ }^{45}$ donde consigna:

Tal vez podemos dividir su vida en tres grandes períodos. El primero, los años de formación (1930-1966), especialmente desde que entra en la Compañía de Jesús (1947) hasta que obtiene su doctorado en filosofía en Madrid. Una constante durante estos años fue el método de formación que siguió para sí mismo, pegándose a los grandes hombres, que según él eran pocos. El hombre grande no era el que tenía gran capacidad 
intelectual, sino el que conocía y enseñaba las cosas de una forma integrada, convencida, no abstracta, innovadora, no atada a reglas. Entre grandes hombres se incluyen: Aurelio Espinoza, Miguel Elizondo, Karl Rahner y Xavier Zubiri.

Un segundo período (19667-1975), señala Falla ${ }^{46}$, es el de innovación con ruptura al interior de la Compañía de Jesús en Centroamérica y al interior de la UCA, en El Salvador. Dentro de la Compañía participa en la evaluación y reprogramación de la entonces Viceprovincia, según lo había pedido el padre Arrupe a toda la orden. Ellacuría fue el principal ideólogo, por así decirlo, de ese examen de conciencia que tuvo como momento más denso los famosos Ejercicios Espirituales para toda la Viceprovincia, en diciembre de 1969, en San Salvador. Esos Ejercicios marcaron un antes y un después, en la historia de la Compañía en Centro América. Ellacuría estructuró los Ejercicios y tuvo las charlas principales, aplicando con una fuerza muy grande los principios de la teología de la liberación a nuestra situación. Cuando volvió de Europa fue inmediatamente nombrado miembro de la Junta de Directores. La UCA llevaba ya casi tres años de existencia. Había nacido desde una corriente social que pretendía hacerle un contrapeso antimarxista a la Universidad de El Salvador. Su orientación era fomentar el desarrollo económico y social de Centro América y El Salvador. Con Ellacuría sin embrago, entrón la orientación de la teología de la liberación en la dirección de la universidad. Desde entonces se concibió a ésta como conciencia crítica del país. Ya no una institución que solo fomentara el desarrollo, sino que propugnara, desde su naturaleza universitaria y desde su inspiración cristiana, por la liberación.

Un tercer período en su vida podría llamarse el del hombre público (1976-1989). Una serie de hitos marcan este ascenso continuo, que hacen de su denuncia universitaria una voz cada vez más fuerte y más luminosa ${ }^{47}$.

Sin embargo, Cardenal ${ }^{48}$ adoptando similar forma de recorrer las circunstancias biográficas de Ignacio Ellacuría señala: "pero otra, quizás más apropiada para un intelectual de su talla, sea hacerlo al hilo de cinco encuentros con personalidades que, sin duda, marcaron su vida de una forma determinante. Cuatro de estas cinco personas son jesuitas y la otra es un laico. Cada una de ellas eximias en espiritualidad ignaciana, humanismo, poesía, teología y filosofía. Estos maestros pusieron los fundamentos a partir de los cuales, Ellacuría configuró su vida y su praxis. Todo ellos fueron determinantes, pero él no repitió a ninguno". 
Es en este sentido que Cardenal' ${ }^{49}$ inicia señalando que el encuentro con la espiritualidad ignaciana lo marca Miguel Elizondo. Ellacuría llegó a El Salvador acompañado de otros cinco novicios y su maestro, Miguel Elizondo. La misión del grupo era abrir el noviciado de la Viceprovincia Centroamericana, en la residencia que los jesuitas tenían junto a la iglesia del Carmen, en la ciudad de Santa Tecla. En Elizondo, Ellacuría y sus compañeros y las generaciones de novicios que los siguieron encontraron a un maestro con gran sentido común, avanzado para su tiempo, y con una espiritualidad profunda. Estas dos características marcaron la vida de los novicios, a quienes introdujo en la Compañía de Jesús.

Elizondo se esforzó por formar a sus novicios en a libertad de espíritu -el elemento esencial de la disponibilidad del futuro jesuita para cumplir con la misión encomendada por sus superiores. En consecuencia, los liberó de lo circunstancial -costumbres, devociones y reglas-y los confrontó con lo fundamental: Jesucristo, los Ejercicios Espirituales de san Ignacio y las Constituciones de la Compañía de Jesús. De esta manera, los fue formando para la disponibilidad y la apertura, par aun futuro que no conocían, pero al cual no debían temer. No obstante el enorme peso de la tradición de la vida religiosa, Elizondo puso en contacto a los novicios con la realidad centroamericana ${ }^{50}$.

Por su parte, apunta Cardenal ${ }^{51}$, que el encuentro con las Humanidades Clásicas lo sostuvo con Aurelio Espinoza en la Universidad Católica de Quito, de la cual era su Rector, de quien al recordar sus clases Ellacuría reconocía la heterodoxia metodológica - "Eran clases realmente creadoras, sin esquemas ya dados-. En cada momento buscaba el ahondamiento nuevo, la recreación viva, el hallazgo imprevisto. Tenían mucho de aventura espiritual y, por ello, parecían todas distintas" —con la que explicaba las obras de valor universal- En el aula, Espinoza discutía los textos seleccionados con gran amor y apasionamiento, comunicando a sus oyentes sus valores humanos, religiosos y morales. "lo que era fundamentalmente en su enseñanza, y seguido audaz y consistentemente sin ningún tipo de discusión, era la preferencia de la educación a la erudición, las formas vitales a los contenidos materiales", escribió Ellacuría ${ }^{52}$. Más tarde, las clases del mismo Ellacuría tenían mucho de esta heterodoxia creadora..

Con Ángel Martínez se da el encuentro con la poesía esencial ${ }^{53}$. Fue en Quito que Ellacuría se encontró con otro jesuita de gran talla intelectual, esta vez se trataba de un poeta navarro muy importante para la poesía 
nicaragüense del siglo XX. Lo que más impactó a Ellacuría fue la síntesis personal que Ángel Martínez había hecho de la poesía, la filosofía y la teología así como también la unidad de su obra y su vida. Para Ángel Martínez, la poesía era una forma de vida: su vida era la poesía y su poesía era su propia vida. Ellacuría supo ver esta unidad esencial de la palabra y vida: todas las dimensiones de su existencia estaban unificadas ${ }^{54}$.

Fue en Karl Rahner que Ellacuría tuvo su encuentro con la teología existencial ${ }^{55}$. En Rahner, Ellacuría encontró un teólogo que hacía teología confrontando ésta con las preguntas planteadas por la vida y cuya vida estaba unida a su obra de manera indisoluble. Se repetía, pues la experiencia que tanto lo había marcado al encontrarse con Aurelio Espinoza y Ángel Martínez, pero ahora en el campo de la teología. Otro aspecto que, sin duda, le impactó de Rahner fue su rigor intelectual ${ }^{56}$.

El encuentro con Xavier Zubiri fue el encuentro con la filosofía de la realidad $^{57}$. Zubiri recibió a Ellacuría con "una enorme sencillez y espontaneidad". El objetivo de la entrevista era pedirle que le dirigiera la tesis doctoral en filosofía.

A propósito del encuentro Zubiri-Ellacuría, Laín Entralgo sostiene ${ }^{58}$ : el atractivo que, a mi modo de ver, ejerció Zubiri en Ellacuría y en todos los que tuvimos el privilegio de tratarlo y hoy de leerlo; y en todos los que tuvimos el privilegio de tratarlo y hoy de leerlo; en que Zubiri, equipado con un conocimiento filosófico y científico plural y profundo -algo poco usual entre filósofos-, elaboró una metafísica, una integral y actualizada filosofía primera. No desistió en esa magna y dura tarea. A ello estaba volcado cuando a inicios de los años sesenta conoció a Ellacuría, quien a su vez recién finalizaba sus estudios teológicos en Innsbruck y, por indicación de sus superiores, tenía entre manos elaborar su tesis doctoral en filosofía. Ignacio, que ya había leído a Xavier, quiso conocerlo personalmente y quiso hacer con él y sobre él su tesis. Fue entonces cuando a mi vez conocí a Ignacio, y fui testigo de los providencial que resultó para la vida y la vocación intelectual de ambos el conocerse y trabajar juntos, pues Zubiri entraba en ese entonces a la etapa de su pensamiento, según él ha confesado, estrictamente metafísica, distanciándose de Heidegger pro situar este gran pensador alemán la ultimidad de las cosas en su idea del ser y no en la realidad como lo hará Zubiri. A precisar su idea de la realidad, su estructura interior, sus diversas formas y figuras; $y$, por otro lado, las distintas maneras con que contamos los hombres para aprehenderla y conceptuarla, era el empeño de Zubiri por ese entonces. Ese afán ocupaba su tiempo y su

555

Vida y obra fllosóllea do Xovier Zubirl, Podro Lón Enhalgo e Ignaclo Ellacuria 
mente cuando conoce a Ellacuría, un joven -tendría éste alrededor de treinta años- con un talento filosófico y teológico prodigiosos, una exquisita formación en ambos saberes, y con un agudo sentido crítico.

Decía que fue providencial para ambos este encuentro. Para Zubiri, porque había encontrado a un idóneo colaborador y discípulo. Llegó a ser, según palabras del propio Zubiri, el "más íntimo y asiduo" de entre todos. Y fue también providencia para Ignacio, pues encontró al deseado y oportuno maestro, un filósofo de ofocio, un metafísico.

El plan de tesis doctoral fue aceptado con mucha dificultad por la Universidad Complutense. Esta rechazó inicialmente el proyecto porque se trataba de una tesis sobre un filósofo vivo. Por otro lado, como Zubiri no tenía ninguna relación formal con la universidad, él y Ellacuría tuvieron que buscar aun catedrático dispuesto a asumir de manera formal la dirección de la tesis, pero sin interferir en su desarrollo. El jurado calificador le otorgó un sobresaliente, en lugar de la calificación máxima suma cum laudes.

En 1967, Ellacuría ingresó en al Sociedad de Estudios y Publicaciones, que le financiaba su viaje anual de San Salvador a Madrid y su estancia en esta ciudad, donde permanecía entre dos y cuatro meses cada año, al lado de Zubiri. Al morir éste, en 1983, Ellacuría quedó como heredero intelectual de su obra y asumió la dirección del Seminario Xavier Zubiri. De esta manera, Ellacuría pasó de discípulo a colega y a amigo entrañable ${ }^{60}$.

Esta andadura iniciada en Portugalete concluye en El Salvador, donde Ellacuría es destinado a la para entonces recién fundada Universidad Centroamericana José Simeón Cañas, a la cual entregaría el resto de su vida y en cuyo recinto moriría asesinado. Desde entonces, Ellacuría pasaría alternando año con año, períodos de tres o cuatro meses en Madrid intensamente involucrado en su quehacer de trabajar con y sobre Zubiri complementado esa tarea con su "enseñar filosofía y teología a la altura de nuestro tiempo con el rigor que el adjetivo "universitario" tan perentoriamente exige y con la orientación que la peculiaridad del pueblo que le rodea, no menos perentoriamente, pide ${ }^{61}$.

Al respecto de la contribución de Ellacuría a la difusión de la filosofía zubiriana, Valdés Valle apunta ${ }^{62}$ : Esto no quiere decir que Ellacuría se convirtiera en un simple asistente de Zubiri, pues nunca lo fue. Pero existía una razón poderosa para que se dedicara a divulgar su pensamiento: su edad avanzada y el temor a que falleciera antes de que pudiera desarrollar 
y publicar su filosofía madura. Esta era una preocupación real en el propio Zubiri, quien reconocía que sin su ayuda personal le sería muy difícil poder concluir su obra.

En total coincidencia con Valdés, Laín Entralgo señala en su carta dirigida a Ellacuría ${ }^{63}$ : "¿Qué haces en Madrid? Ante todo, ayudas filial y fraternalmente a Zubiri. Con tu gran inteligencia, tu ancho saber y tu fino discernimiento, sirves de apoyo intelectual y afectivo a Zubiri, para que éste, en la plenísima y luminosa madurez de sus setenta y ocho años, siga haciendo filosofía".

Este pendular de San Salvador-Madrid y viceversa, continúa desde el inicio de los sesentas; y a la muerte de Zubiri en 1983, Ellacuría sigue dirigiendo la publicación de sus obras en el marco de la Fundación Xavier Zubiri, presidida por Ellacuría.

Quedaría incompleta la lista de personalidades que marcaron la vida de Ellacuría en forma determinante si no incluyéramos su encuentro con Monseñor Oscar Romero, su último maestro, esta vez en la $\mathrm{fe}^{64}$; al respecto de lo cual Sobrino señala ${ }^{65}$ : "Con estas palabras Ellacuría confesaba humildemente - a lo que no era muy dado- la deuda de la UCA con Monseñor. Pero yo leo esas palabras también como el reconocimiento de su deuda personal con Monseñor en lo más hondo de su persona. Pero, además, en un momento clave del discurso Ellacuría vuelve a relacionar a monseñor Romero con Dios.

Sobre dos pilares apoyaba [Monseñor Romero] su esperanza: un pilar histónico que era su conocimiento del pueblo al que él atribuía una capacidad inagotable de encontrar salidas a las dificultades muy graves, y un pilar trascendente que era su persuasión de que últimamente Dios es un Dios de vida y no de muerte, que lo último de la realidad es el bien y no el mal. Esa esperanza no sólo le hacía superar cualquier tentación de desaliento sino que le animaba a seguir trabajando, consciente de que su esfuerzo no iba a ser baldío por más que fuera corto el tiempo.

En conclusión, Ellacuría vio en monseñor Romero a un hombre de Dios y vio a Dios en ese hombre. La verdad y la profecía, la misericordia y la justicia, la utopía y la gracia, y la difícil simultaneidad de todo ello que afloraba sin límites en Monseñor, le hizo —indefensamente- presente a Dios. En Monseñor vio, creo yo, que se hacía realidad el deseo que todos llevamos dentro: que Dios es bueno y que es bueno que haya Dios. 
A manera de colofón: un testimonio de gratitud.

Como muchas, la familia del autor de este título fue reclamada, por convieciones de justicia social, a tener determinado nivel de participación del lado del movimiento insurgente en el pasado conflicto armado. Ello nos enfrentó a las situaciones límite que toda guerra conlleva.

Confieso lo anterior, movido por el genuino interés de reconocer la deuda de gratitud que en lo personal guardo con Ignacio Ellacuría y todos los demás mártires de la UCA, que con su muerte no hicieron más que refrendar con el sacrificio de sus vidas lo que el padre José María Tojeira ${ }^{66}$ señala que escuchó a Ellacuría repetir con frecuencia "Nuestro trabajo fundamental consiste en salvar vidas". No sólo a través de la denuncia de la barbarie y por medio de la presentación brillante de la racionalidad de la salida negociada, sino a través de todas las acciones de la vida cotidiana, como bien lo señala Tojeira ${ }^{67}$ lo hizo siempre Ellacuría.

Ciertamente, mi vida pudo ser una de esas vidas salvadas que hoy tienen la oportunidad de reconocer con gratitud el hecho de que para Ellacuria "el bien más universal" que ignacianamiente persiguió al llegar a El Salvador fuera influir para que la realidad del país, Centroamérica y del Tercer Mundo, se configuraran como "tierra nueva" para una nueva humanidad ${ }^{68}$.

Sirva entonces este artículo para refrendarle gratitud a los mártires de la UCA en ocasión de cumplirse este noviembre el XVI aniversario de su muerte martirial. 
1 San Baldomero Ucar, J.M.: " El significado de la filosofía de Xavier Zubiri en la filosofía española". htcp://www.zubiri.org./works/spanishworksabout/sanbaldomero/ lección 1998.htm (30/04/04).

2 Cañas López, S. A.: "Pedro Laín Entralgo: Medicina e Historia". Realidad Revista de Ciencias Sociales,y Humanidades \# 98 Marzo-Abril 2004. UCA Editores. Pág. 185-194.

'Laín Entralgo, P. “Antropología Médica”. Salvat Editores. Barcelona. 1984

- Mariáregui, J. "Necrología de Don Pedro Laín Entralgo (1908-2001)". Revista de Neuro-Psiquiatría. 2001. 64: 279-286.

s San Baldomero Úcar, J.M.: “ El significado de la filosofía de Xavier Zubiri en la filosolía española". htcp://www.zubiri.org./works/spanishworksabout/sanbaldomero/ lección 1998.htm (30/04/04).

- Inguanzo, J.L. "Vida y obra de Xavier Zubiri". Junio 2001. http://www.pue.uja.mx/ docedu/revista/revistaUNO/vida.html (30/04/04). El paréntesis es nuestro.

, Ibid.

- San Baldomero Úcar, J.M. “El significado de la filosoffa de Xavier Zubiri”. Octubre de 1998. http://www.zubiri.org/works/spanishworksabout/sanbaldomero/ leccion1998.htm

9 Inguanzo, J.L. "Vida y obra de Xavier Zubiri". Op. Cit.

10 San Baldomero Úcar, J.M. “El significado de la filosofla de Xavier Zubiri”. Op. Cit.

"Inguanzo, J.L. "Vida y obra de Xavier Zubiri". Op. Cit.

12 Laín Entralgo, P. "Mi Xavier Zubiri". Antropos 201:43-54.

13 Ibid. Pág. 45

14 Inguanzo, J.L. "Vida y obra de Xavier Zubiri". Op. Cit.

is San Baldomero Ucar, J.M. “El significado de la filosofía de Xavier Zubiri”. Op. Cit.

16 Inguanzo, J.L. "Vida y obra de Xavier Zubiri". Op. Cit.

17 San Baldomero Ucar, J.M. “El significado de la filosofía de Xavier Zubiri”. Op. Cit.

18 Inguanzo, J.L. "Vida y obra de Xavier Zubiri". Op. Cit.

19 San Baldomero Ucar, J.M. "El significado de la filosofía de Xavier Zubiri". Op. Cit.

20 Ibid.

2I Laín Entralgo, P. "Mi Xavier Zubiri” Op. Cit.

22 Baldomero Ucar, J.M. "El significado de la filosofía de Xavier Zubiri". Op. Cit.

23 Ibid

24 Ibid 
Inguanzo, J.L. "Vida y obra de Xavier Zubiri". Op. Cit.

26 San Baldomero Úcar, J.M. "El significado de la filosofía de Xavier Zubiri". Op. Cit.

27 San Baldomero Úcar, J.M. "El significado de la filosofía de Xavier Zubiri". Op. Cit

28 Laín Entralgo, P. "Mi Xavier Zubiri". Op. Cit. Pág. 47.

29 Inguanzo, J.L "Vida y obra de Xavier Zubiri". Op. Cit

so Ibíd.

"I San Baldomero Ucar, J.M. “El signifiado de la filosofía de Xavier Zubiri. Op. Cit.

3 Ibid.

33 Ibid.

34 Ibid.

35 Ibid.

36 Ibid.

37 Ibid.

38 Laín Entralgo, P. "En el centenario de Zubiri". El País. España, 31-12-1998. http:// mipagina.euskaltel.es/adaher/index.htm.

39 Ibid.

10 Marías, J. "Laín Entralgo: su magnitud real". ABC Madrid 21de Junio de 2001. http://www.filosofia.org/hem/200/20010621.htm

1) Orringer, N.R "Pedro Laín Entralgo: educador, humanista, hombre". Universidad de Connecticut. S/f http://adigital.pntic.mec.es/ tronchon/lain/ponenciahtm (junio de 2004).

2 Sánchez Torres, F. "Aproximación a Pedro Laín Entralgo". http:// www.encolombia.com/medicina/academedicina23357 (14/11/03).

4) Oringer, N.R “Pedro Laín Entralgo: educador, humanista y hombre”. Op. Cit.

4 Ibid.

45 Falla, R "Subiendo a Jerusalén. (semblanza)". En Sobrino, J. Y Alvarado, R "Ignacio Ellacuría. Aquella libertad esclarecida". UCA Editores. San Salvador. 1999. Págs. 29-42.

16 Ibid.

47 Ibid.

4 Cardenal, R. "De Portugalete a San Salvador de la mano de cinco maestros". En Sobrino, J. y Alvarado, R. Ignacio Ellacuria. Aquella libertad esclarecida. Op. Cit.

49 Ibíd., Pág. 29

so Ibid., Pág. 44

sI lbid., Pág. 45 
52 Citado por Cardenal de: Ellacuría, I. "El padre Aurelio Espinoza Pólit, S.J." ECA, $178,1963,21$

3) Cardenal, $R$ "De Porrugalete a San Salvador: de la mano de cinco maestros". Op. Cit. Pág. 47

34 Ibid., Pág. 48

53 Ibid., Pág. 51

so Ibid., Pág. 52

s7 Ibid., Pág. 53

58 Laín Entralgo, P. "El discipulado zubiriano". En Sobrino, J. y Alvarado, R. Ignacio Ellacuria. Aquella libertad esclarecida. UCA Editores. 1999. Pág. 93-102.

s9 Cardenal, R: “De Portugalete a San Salvador: de la mano de los maestros " Op. Cit. Pag. 55

ilbid., Pág. 56

6 Ibid.

62 Valdés Valle, R “La búsqueda filosófica inicial” En Sobrino, J. y Alvarado, R Opus cit. Pág. 81.

6) Lain Entralgo, P. "El discipulado zubiriano". En Sobrino, J. y Alvarado, R. Opus cit. Pág. 100.

a Cardenal, $\mathrm{R}$ “De Portugalete a San Salvador de la mano de cinco maestros”. Opus cit. Pág. 58

65 Citado por Sobrino de "La UCA ante el doctorado concedido a monseñor Romero", ECA, 437 (1985) 174.

* Tojeira, J.M. Aquella libertad esclarecida. En Sobrino J. y Alvarado R., "Ignacio Ellacuría: Aquella libertad esclarecida". Op. Cic. Página 342

67 Ibid.

6R Hernández Pico, J. "Ellacuría, ignaciano". En Sobrino J. y Alvarado R, “Ignacio Ellacuría: Aquella libertad esclarecida". Op. Cit. Página 334 